\title{
Validation and quality assurance applied to goat milk chemical composition: Minerals and trace elements measurements
}

\author{
Inês Trancoso ${ }^{1}$, Luísa B. Roseiro ${ }^{2}$, António P.L. Martins ${ }^{3}$, Maria A. Trancoso ${ }^{2 *}$ \\ ${ }^{1}$ ISA, Tapada da Ajuda, Lisboa, Portugal \\ ${ }^{2}$ INETI, Estrada do Paço do Lumiar 22, 1649 Lisboa, Portugal \\ ${ }^{3}$ INIA-INRB, ISA, Tapada da Ajuda, Lisboa, Portugal
}

Received 2nd October 2008 - Accepted 18 February 2009

\begin{abstract}
In the present study, quality assurance programmes were implemented to validate and control the analytical methodologies used for the characterization of minerals and trace elements in goat milk from Portuguese breeds. With the exception of chloride that was determined by potentiometric titration, all the other elements were determined by spectroscopic techniques after different sample decomposition: $\mathrm{P}$ was measured by ultraviolet-visible molecular absorption spectrometry, $\mathrm{Ca}, \mathrm{Fe}, \mathrm{K}, \mathrm{Mg}, \mathrm{Mn}, \mathrm{Na}$ and $\mathrm{Zn}$ by flame atomic absorption spectrometry and $\mathrm{Cd}, \mathrm{Co}$, $\mathrm{Cr}, \mathrm{Cu}, \mathrm{Mo}, \mathrm{Ni}$ and $\mathrm{Pb}$ by electrothermal atomic absorption spectrometry. The methods performance characteristics, namely specificity, limit of detection, limit of quantification, working range, precision and trueness were evaluated. Measurement uncertainty was expressed in terms of precision and trueness. Precision under intralaboratory reproducibility conditions was estimated from triplicate analysis, and the trueness component was estimated in terms of overall recovery using either skim milk powder certified reference materials or spiked samples. The results obtained are discussed on the basis of the performance criteria required by EC regulations to verify when a method is suitable for food control. The methods used for the characterization of minerals and trace elements in goat milk complied with EC requirements since there was no matrix influence, the Horrat values were $<2.0$, recoveries were within the interval $1.00 \pm 0.10$ for minerals and $1.00 \pm 0.20$ for trace elements and the combined uncertainty of the results were lower than the maximum standard uncertainty calculated using the uncertainty function approach. In relation to the limits of detection and quantification, the limits obtained for $\mathrm{Pb}$ were lower than those specified by EC regulation.
\end{abstract}

quality assurance / goat milk / trace element / mineral / analysis

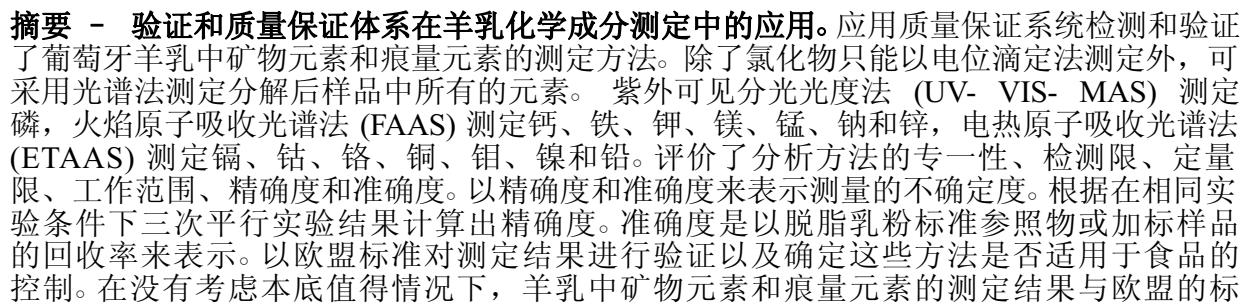

*Corresponding author (通讯作者): maria.trancoso@ineti.pt 
准进行了对比, 结论是 Horrat 值低于 2.0 , 矿物元素与痕量元素的回收率分别在 $1.00 \pm 0.10$ 和 $1.00 \pm 0.20$, 不确定度低于用不确定性函数计算的最大标准不确定, 只有铅的检测限和 定量限低于欧盟标准。

\section{质量保证 / 羊奶 / 微量元素 / 矿物元素 / 分析}

Résumé - Validation et assurance qualité appliquée à la composition chimique du lait de chèvre : mesures des minéraux et éléments traces. Dans ce travail, des programmes d'assurance de la qualité ont été mis en œuvre afin de valider et de contrôler les méthodes d'analyse utilisées pour caractériser les minéraux et les éléments traces du lait de chèvres de race portugaise. À l'exception du chlorure, qui a été déterminé par titrage potentiométrique, tous les autres éléments ont été déterminés par différentes techniques spectroscopiques après décomposition de l'échantillon : $\mathrm{P}$ a été mesuré par spectrométrie d'absorption moléculaire ultraviolet-visible (UV-VIS-MAS), Ca, $\mathrm{Fe}, \mathrm{K}, \mathrm{Mg}, \mathrm{Mn}, \mathrm{Na}$, et $\mathrm{Zn}$ par spectrométrie d'absorption atomique de flamme (FAAS) et Cd, Co, $\mathrm{Cr}, \mathrm{Cu}, \mathrm{Mo}, \mathrm{Ni}$ et $\mathrm{Pb}$ par spectrométrie d'absorption atomique électrothermique (ETAAS). Les caractéristiques de performance des méthodes, à savoir la spécificité, limite de détection, limite de quantification, la plage de travail, la précision et la justesse ont été évaluées. Les incertitudes de mesure ont été exprimées en termes de précision et de justesse. La précision sous des conditions de reproductibilité intralaboratoire a été estimée à partir des analyses en triple. La justesse a été estimée en termes de récupération globale, soit en utilisant des poudres de lait matériaux de référence certifiés ou des échantillons dopés. Les résultats obtenus sont discutés sur la base des critères de performance requis par les règlements $\mathrm{CE}$ pour vérifier qu'une méthode est adaptée au contrôle des aliments. Les méthodes utilisées pour la caractérisation des minéraux et des éléments traces dans le lait de chèvre se conformaient aux exigences de la CE car il n'y avait pas d'influence de la matrice, les valeurs de Horrat étaient inférieures à 2,0; les récupérations étaient dans l'intervalle $1,00 \pm 0,10$ pour les minéraux et dans l'intervalle $1,00 \pm 0,20$ pour les élements traces et l'incertitude combinée des résultats était inférieure à l'incertitude normalisée maximale, calculée en utilisant la fonction de l'incertitude. En ce qui concerne les limites de détection et de quantification, nos limites calculées pour le plomb étaient inférieures à celles spécifiées par le règlement $\mathrm{CE}$.

assurance qualité / lait de chèvre / élément trace / minéraux / analyse

\section{INTRODUCTION}

Minor compounds such as minerals and trace elements are an important group of milk nutrients required by the human body in limited amounts for optimal function. The existing literature on minerals and trace elements composition of milk is in general scarce, and in Portugal, this is particularly true, namely for milk from indigenous goat breeds. Goat milk has been gaining an increased importance in the human diet, due to its unique properties that distinguish it from cow milk [20]. As an example, recent studies carried out at the University of Granada, Spain demonstrated the beneficial effect of goat milk, with respect to cow milk, on the metabolism and bioavailability of iron, copper, zinc and selenium in control rats, especially those with malabsorption syndrome or induced ferropaenic anaemia $[2,5,7]$.

On the other hand, pollution resulting from industrialization and the increasing number of cars causes the harmful elements absorbed by soil find their way to plants that constitute feeding stuff, ending up in animal products, including milk.

In this context, reliable analytical measurements are essential to estimate the content of minerals and trace elements in milk, to monitor influences from the environment on the levels of those elements, to control possible secondary contaminations or essential element losses during processing, storage and packaging of milk, and to estimate the 
role of trace element contents with regard to product quality or health risks.

The quality of chemical measurements is supported by validation of methods, uncertainty and traceability of the results. Validation of methods aims to demonstrate that a method is applicable both to a specified test at a defined concentration level of the analyte and to provide a quantitative estimation of the measurements reliability. Uncertainty and traceability of the results give the information needed to know their metrological quality allowing comparability $[8,9]$.

Nowadays, results with uncertainty are required for ISO accredited methods and facilitate the interpretation of results. In food control, there is a high need of comparability of the results. Specific validation of methods and quality assurance programmes either for establishment and evaluation of the method performances or to confirm the fit for purpose are necessary even when performing standardized methods [13].

European Regulation 333/2007/EC [25] establishes the performance of analytical criteria (applicability, precision, recovery, limits of detection and quantification and specificity) specified on the basis of the legal limits fixed by European Regulation 1881/2006/EC [24] amended by European Regulation 629/2008/EC [26]. The Directive 2005/4/EC [23] and European Regulation 333/2007/EC [25] refer that analytical results must be reported and interpreted in a uniform way, to ensure a harmonized approach across the EC. Reporting analytical results with estimation of uncertainty is the tool to achieve those tasks.

In the present study, raw goat milk from the indigenous Portuguese breed Serpentina was studied to characterize the concentration ranges of minerals and trace elements. Raw goat milk samples were collected at well-defined restricted geographical area, from a herd previously selected to warrant reliable data, into decontaminated plastic containers with rigorous precautions to minimize any possible source of exogenous contamination.

Quality assurance/quality control programmes were implemented to validate and to control the analytical methodologies used. The precision was monitored through triplicate analyses, and trueness was evaluated using both certified reference materials (CRMs) and spiked samples. The uncertainty of the results was estimated using an intralaboratory relative approach based on the validation studies and the quality control data. This model was supported by the definition of accuracy, which comprises trueness and precision.

\section{MATERIALS AND METHODS}

\subsection{Reagents and solutions}

All solutions were prepared using ultrapure water of $18 \mathrm{M} \Omega \cdot \mathrm{cm}^{-1}$ resistivity supplied from a Millipore Milli-Q water purification system (Millipore, Bedford, $\mathrm{MA})$. The reagents used in digestion were $\mathrm{HNO}_{3}$ 65\% (w/v) and $\mathrm{H}_{2} \mathrm{O}_{2} 30 \%(\mathrm{w} / \mathrm{v})$ Suprapur grade from Merck, Darmstadat, Germany.

Calibration standard (CS) solutions for each element determined by atomic absorption spectrometry (AAS) were prepared, just before use, by diluting Merck Spectrosolgrade mono-elemental stock standard solutions of $1000 \mathrm{mg} \cdot \mathrm{L}^{-1}$ of each element. Mono-elemental quality control standard (QCS) solutions were prepared, just before use, as described for CS solutions, however using an independent $1000 \mathrm{mg} \cdot \mathrm{L}^{-1}$ standard solution.

Matrix modifiers of magnesium, $\mathrm{c}(\mathrm{Mg})=(10.0 \pm 0.2) \mathrm{g} \cdot \mathrm{L}^{-1} ; \quad$ palladium $\mathrm{c}(\mathrm{Pd})=(10.0 \pm 0.2) \mathrm{g} \cdot \mathrm{L}^{-1}$ and phosphate $\mathrm{c}\left(\mathrm{NH}_{4} \mathrm{H}_{2} \mathrm{PO}_{4}\right)=(100 \pm 2) \mathrm{g} \cdot \mathrm{L}^{-1}$ graphite furnace grade were used (Merck, Germany).

$\mathrm{NaCl} 0.025 \mathrm{~mol} \cdot \mathrm{L}^{-1}$ standard solution was prepared by dissolving $1.4614 \mathrm{~g} \mathrm{NaCl}$, previously dried at $105^{\circ} \mathrm{C}$, in water and 
diluted to $1000 \mathrm{~mL} . \mathrm{AgNO}_{3} 0.01 \mathrm{~mol} \cdot \mathrm{L}^{-1}$ standard solution was prepared by appropriate dilution of $\mathrm{AgNO}_{3}$ tritrisol from Merck, Germany.

\subsection{CRMs}

The CRMs used in this study, BCR - 151 (trace elements in spiked skim milk powder) and BCR - 063R (skim milk powder), were purchased from the European Institute for Reference Materials and Measurements (ERM, formerly known as BCR). These CRMs were selected considering the target concentration of the analytes and how they match the matrix under consideration.

\subsection{Milk samples}

Milk from a flock of a Portuguese indigenous goat breed (Serpentina) with $>50$ heads was collected at their local production area (Valeverde, Alentejo). The milk production system was extensive and all the animals had certification for pure Serpentina breed. Milk was obtained twice a day by machine milking. For this study, milk samples were collected from the bulk-holding tanks once a month during the lactation period (between October 2007 and May 2008) at their local production area. Milk samples were then brought refrigerated to the laboratory for further analysis.

\subsection{Analytical procedure}

Total content of minerals and trace elements in goat milk were determined by AAS, with the exception of chloride quantification. The mass fraction, $w\left(\mathrm{mg} \cdot \mathrm{kg}^{-1}\right)$ of each element was calculated using the equation:

$$
w=\frac{C \times V}{m} \times F_{\mathrm{dil}},
$$

where $C$ is the concentration of the elements on the digestion solution $\left(\mathrm{mg} \cdot \mathrm{L}^{-1}\right)$,
$V$ is the volume of the sample digestion solution (L), $m$ is the mass of sample taken for analysis $(\mathrm{g})$ and $F_{\text {dil }}$ is the dilution factor of the milk digestion solution to bracket the calibration curve and use direct calibration against standard solutions minimizing matrix influence on calibration.

An adapted potentiometric titration method was used for chloride quantification $\left(\mathrm{mg} \cdot \mathrm{kg}^{-1}\right)$ in milk $[11,14]$, and for which no sample decomposition was needed:

$$
\begin{aligned}
w_{\mathrm{Cl}}= & \frac{\left(V_{\mathrm{AgNO}_{3}}-V_{B_{\text {reag }}}\right) \times C_{\mathrm{AgNO}_{3}} \times 10^{3}}{m} \\
& \times 35.455
\end{aligned}
$$

where $V_{\mathrm{AgNO}_{3}}$ and $V_{B_{\text {reag }}}$ are the volumes $(\mathrm{mL})$ of titrating and reagent blank, respectively, and $C_{\mathrm{AgNO}_{3}}$ is the concentration of $\mathrm{AgNO}_{3}\left(\mathrm{~mol} \cdot \mathrm{L}^{-1}\right)$ and 35.455 is the molar mass of chloride $\left(\mathrm{g} \cdot \mathrm{mol}^{-1}\right)$.

\subsubsection{Digestion}

Milk samples $(\sim 2 \mathrm{~g})$ and CRMs $(\sim 0.4 \mathrm{~g})$ were weighed in a microwave vessel, and $3 \mathrm{~mL}$ of $\mathrm{HNO}_{3}(65 \%), 1 \mathrm{~mL}$ of $\mathrm{H}_{2} \mathrm{O}_{2}(30 \%)$ and $5 \mathrm{~mL}$ of water were added. The microwave system was set up at a maximum power of $1000 \mathrm{~W}$ as follows: temperature increases to $195^{\circ} \mathrm{C}$ at a rate of $17{ }^{\circ} \mathrm{C} \cdot \mathrm{min}^{-1}$ and hold at $195{ }^{\circ} \mathrm{C}$ for $20 \mathrm{~min}$. After cooling, the carousel was removed from the oven, the Teflon vessels were uncapped and the samples were diluted to $100 \mathrm{~mL}$ using water. All sample digestion solutions were clear. This constitutes working solution A.

A Milestone ETHOS Plus Microwave Labstation (Milestone, Sorisole, Italy) to assisted wet digestions on closed vessels was used. The reaction vessels were cleaned with $5 \mathrm{~mL}$ of $1 \mathrm{~mol} \cdot \mathrm{L}^{-1} \mathrm{HNO}_{3}$ solution before each digestion. 
Table I. Instrumental and operating conditions for FAAS.

\begin{tabular}{lccccc}
\hline Element & $\begin{array}{c}\text { Wavelength } \\
(\mathrm{nm})\end{array}$ & $\begin{array}{c}\text { Lamp current } \\
(\mathrm{mA})\end{array}$ & $\begin{array}{c}\text { Slit width } \\
(\mathrm{nm})\end{array}$ & $\begin{array}{c}\text { Background } \\
\text { correction }\end{array}$ & Flame chemistry $^{\mathrm{a}}$ \\
\hline $\mathrm{Na}$ & 589.0 & 6 & 0.2 & - & $\mathrm{Air} / \mathrm{C}_{2} \mathrm{H}_{2}-$ stoichiometric \\
$\mathrm{K}$ & 766.5 & 7 & 0.5 & - & $\mathrm{Air} / \mathrm{C}_{2} \mathrm{H}_{2}-$ stoichiometric \\
$\mathrm{Ca}$ & 422.6 & 5 & 0.5 & - & $\mathrm{N}_{2} \mathrm{O} / \mathrm{C}_{2} \mathrm{H}_{2}-$ reducing \\
$\mathrm{Mg}$ & 285.2 & 3 & 0.5 & - & $\mathrm{Air} / \mathrm{C}_{2} \mathrm{H}_{2}-$ stoichiometric \\
$\mathrm{Zn}$ & 213.9 & 8 & 0.2 & $\mathrm{D}_{2}$ lamp & $\mathrm{Air} / \mathrm{C}_{2} \mathrm{H}_{2}-$ stoichiometric \\
$\mathrm{Fe}$ & 248.3 & 10 & 0.2 & $\mathrm{D}_{2}$ lamp & $\mathrm{Air} / \mathrm{C}_{2} \mathrm{H}_{2}-$ stoichiometric \\
$\mathrm{Mn}$ & 279.5 & 10 & 0.2 & - & $\mathrm{Air} / \mathrm{C}_{2} \mathrm{H}_{2}-$ stoichiometric \\
\hline
\end{tabular}

- Without background correction.

${ }^{a}$ Burner position: aligned with optical axis.

\subsubsection{Dry ashing digestion}

For dry ashing digestion, a Labotherm L9/SH furnace was used (Naberherm, Germany). Milk samples $(\sim 25 \mathrm{~g})$ and CRMs $(\sim 5 \mathrm{~g}+20 \mathrm{~mL}$ of water $)$ were placed in $90-\mathrm{mL}$ platinum dishes with $70 \mathrm{~mm}$ diameter and $35 \mathrm{~mm}$ height.

The furnace temperature programme used in this study was an adaptation of ISO 8070 [15] as follows: temperature increase from 25 to $100{ }^{\circ} \mathrm{C}$ at a rate of $2.5{ }^{\circ} \mathrm{C} \cdot \mathrm{min}^{-1}$; hold at $100{ }^{\circ} \mathrm{C}$ for $2.5 \mathrm{~h}$, increase at a rate of $1{ }^{\circ} \mathrm{C} \cdot \mathrm{min}^{-1}$ to $200{ }^{\circ} \mathrm{C}$; hold at $200{ }^{\circ} \mathrm{C}$ for $1 \mathrm{~h}$, increase at a rate of $4{ }^{\circ} \mathrm{C} \cdot \mathrm{min}^{-1}$ to $300{ }^{\circ} \mathrm{C}$; hold at $300{ }^{\circ} \mathrm{C}$ for $1 \mathrm{~h}$ and increase at a rate of $4{ }^{\circ} \mathrm{C} \cdot \mathrm{min}^{-1}$ to $550{ }^{\circ} \mathrm{C}$; hold at $550^{\circ} \mathrm{C}$ for $6 \mathrm{~h}$. The white residues were dissolved in $0.5 \mathrm{~mL}$ of $\mathrm{HNO}_{3}$ $(25 \% \mathrm{v} / \mathrm{v})$ and $5 \mathrm{~mL}$ of water, heating the mixture slowly. The solution was transferred into a $25 \mathrm{~mL}$ volumetric flask and made up to volume with water. This constitutes working solution B.

\subsubsection{Flame atomic absorption spectrometry}

Flame atomic absorption spectrometry (FAAS) was used to determine the total metal concentrations in the milk digestion solutions, namely $\mathrm{Na}, \mathrm{K}, \mathrm{Ca}, \mathrm{Mg}$ and $\mathrm{Zn}$ in solution $\mathrm{A}$ and $\mathrm{Fe}$ and $\mathrm{Mn}$ in solution $\mathrm{B}$ :
$F_{\text {dil }}=50$ for $\mathrm{K}$ and $\mathrm{Na} ; F_{\text {dil }}=12.5$ for $\mathrm{Ca}$ and $\mathrm{Mg} ; F_{\text {dil }}=1.25$ for $\mathrm{Fe}$ and $\mathrm{Mn}$ and $F_{\text {dil }}=1$ for $\mathrm{Zn}$ [3].

The FAAS was carried out on a SOLAAR M Series Thermo Electron spectrometer, equipped with deuterium lamp background correction system, using hollow-cathode lamps (Thermo Electron Corpor., Cambridge, UK) as radiation source at each element. In Table I, the FAAS instrumental and operational conditions (including the elements where correction with deuterium was used) are summarized. The atomic absorption spectrometer was optimized to the maximum of absorption at the wavelength selected for the element before each analytical calibration procedure. The instrument was found in good operative conditions when the absorbance of the standard was $\pm 20 \%$ of the manufacturer's values. This step allows operating on a daily basis with an identical instrument performance.

For the measurements, calibration blank and standard solutions (at least five) were used, namely $\mathrm{Na}$ and $\mathrm{K}$ in $0.1 \mathrm{~mol} \cdot \mathrm{L}^{-1}$ $\mathrm{HNO}_{3}$ (suprapur); $\mathrm{Ca}$ and $\mathrm{Mg}$ in $\mathrm{HCl}$ $0.5 \mathrm{~mol} \cdot \mathrm{L}^{-1}$ solution with $6 \mathrm{~g} \cdot \mathrm{L}^{-1}$ of $\mathrm{La}_{2} \mathrm{O}_{3} ; \mathrm{Fe}$ and $\mathrm{Mn}$ in $\mathrm{HCl} 0.5 \mathrm{~mol} \cdot \mathrm{L}^{-1}$ solution containing $50 \mathrm{mg} \cdot \mathrm{L}^{-1}$ of $\mathrm{Ca}$ and $\mathrm{Zn}$ in $\mathrm{HNO}_{3} 0.5 \mathrm{~mol} \cdot \mathrm{L}^{-1}$ solution.

Each absorbance value was the average of three absorbance readings with 3-s integration time. 
Table II. Instrumental parameters and electrothermal programmes for ETAAS.

\begin{tabular}{|c|c|c|c|c|c|c|c|c|c|}
\hline & & & $\mathrm{Cd}$ & Co & $\mathrm{Cr}$ & $\mathrm{Cu}$ & Mo & $\mathrm{Ni}$ & $\mathrm{Pb}$ \\
\hline \multirow[t]{6}{*}{ Parameters } & \multicolumn{2}{|c|}{ Wavelength (nm) } & 228.8 & 240.7 & 357.9 & 324.8 & 313.3 & 232.0 & 217.0 \\
\hline & \multicolumn{2}{|c|}{ Slit width $(\mathrm{nm})$} & 0.5 & 0.2 & 0.2 & 0.5 & 0.5 & 0.2 & 0.5 \\
\hline & \multicolumn{2}{|c|}{ Lamp current (mA) } & 5 & 10 & 9 & 4 & 12 & 12 & 10 \\
\hline & \multicolumn{2}{|c|}{ Sample volume $(\mu \mathrm{L})$} & 15 & 15 & 10 & 10 & 20 & 20 & 15 \\
\hline & \multicolumn{2}{|c|}{ Modifier volume $(\mu \mathrm{L})$} & 5 & 5 & 10 & 10 & 0 & 0 & 5 \\
\hline & \multicolumn{2}{|c|}{ Zeeman background correction } & Yes & Yes & Yes & Yes & Yes & Yes & Yes \\
\hline \multirow{15}{*}{$\begin{array}{l}\text { Graphite } \\
\text { furnace } \\
\text { steps }\end{array}$} & \multirow[t]{3}{*}{ Drying 1} & Temperature $\left({ }^{\circ} \mathrm{C}\right)$ & 100 & 100 & 100 & 100 & 100 & 95 & 100 \\
\hline & & Time (s) & 30 & 30 & 10 & 30 & 30 & 10 & 30 \\
\hline & & Ramp time $\left({ }^{\circ} \mathrm{C} \cdot \mathrm{s}^{-1}\right)$ & 10 & 10 & 10 & 10 & 10 & 8 & 10 \\
\hline & \multirow[t]{3}{*}{ Drying 2} & Temperature $\left({ }^{\circ} \mathrm{C}\right)$ & 150 & 150 & 150 & - & 150 & 150 & 150 \\
\hline & & Time (s) & 20 & 15 & 10 & - & 40 & 20 & 15 \\
\hline & & Ramp time $\left({ }^{\circ} \mathrm{C} \cdot \mathrm{s}^{-1}\right)$ & 20 & 20 & 15 & - & 10 & 3 & 20 \\
\hline & \multirow[t]{3}{*}{ Pyrolysis } & Temperature $\left({ }^{\circ} \mathrm{C}\right)$ & 700 & 1500 & 1300 & 700 & 1800 & 700 & 800 \\
\hline & & Time (s) & 20 & 20 & 10 & 20 & 20 & 20 & 40 \\
\hline & & Ramp time $\left({ }^{\circ} \mathrm{C} \cdot \mathrm{s}^{-1}\right)$ & 150 & 3 & 130 & 150 & 150 & 13 & 150 \\
\hline & \multirow[t]{3}{*}{ Atomization } & Temperature $\left({ }^{\circ} \mathrm{C}\right)$ & 1500 & 2500 & 2500 & 2400 & 2800 & 2300 & 1600 \\
\hline & & Time (s) & 3 & 3 & 3 & 3 & 3 & 2.5 & 3 \\
\hline & & Ramp time $\left({ }^{\circ} \mathrm{C} \cdot \mathrm{s}^{-1}\right)$ & 0 & 0 & 0 & 0 & 0 & 0 & 0 \\
\hline & \multirow[t]{3}{*}{ Cleaning } & Temperature $\left({ }^{\circ} \mathrm{C}\right)$ & 2400 & 2600 & 2600 & 2500 & 2850 & 2500 & 2500 \\
\hline & & Time (s) & 3 & 3 & 3 & 3 & 3 & 2 & 3 \\
\hline & & Ramp time $\left({ }^{\circ} \mathrm{C} \cdot \mathrm{s}^{-1}\right)$ & 0 & 0 & 0 & 0 & 0 & 0 & 0 \\
\hline
\end{tabular}

\subsubsection{Electrothermal atomic absorption spectrometry}

$\mathrm{Cd}, \mathrm{Co}, \mathrm{Cr}, \mathrm{Cu}, \mathrm{Mo}, \mathrm{Ni}$ and $\mathrm{Pb}$ were determined by electrothermal atomic absorption spectrometry (ETAAS) [12] in solution $\mathrm{B}$ after appropriate dilution $\left(F_{\mathrm{dil}}=\right.$ 3 for $\mathrm{Co}$ and $\mathrm{Mo} ; F_{\text {dil }}=5$ for $\mathrm{Cd}, \mathrm{Pb}$ and $\mathrm{Ni}$ and $F_{\text {dil }}=10$ for $\mathrm{Cu}$ and $\mathrm{Cr}$ ).

ETAAS was performed in a SOLAAR M Series Thermo Electron spectrometer equipped with a GF95Z Zeeman furnace head, an FS 95 furnace autosampler (Thermo Electron Corpor., Cambridge, UK). Pyrolytic graphite tubes (Thermo Scientific, Germany) were used. ETAAS instrumental conditions (including the elements where Zeeman correction was used) and electrothermal programmes used are given in Table II.

Sample volumes, ramp and hold times for drying, ashing, atomization and cleaning temperatures were optimized to obtain the maximum absorbance and minimal background. During the analysis, the flow rate through the graphite tube was $0.2 \mathrm{~L} \cdot \mathrm{min}^{-1}$ except for Mo in the cleaning step $\left(0.3 \mathrm{~L} \cdot \mathrm{min}^{-1}\right)$, and flow rate was interrupted during atomization. The signals were processed in peak height mode.

Matrix modifiers were injected into the graphite tube with the sample digestion solutions as follows: $200 \mu \mathrm{g} \mathrm{NH}_{4} \mathrm{H}_{2} \mathrm{PO}_{4}$ for $\mathrm{Cd}$ and $\mathrm{Pb} ; 50 \mu \mathrm{g} \mathrm{Mg}\left(\mathrm{NO}_{3}\right)_{2}$ for $\mathrm{Co}$, $\mathrm{Cr}$ and $50 \mu \mathrm{g} \mathrm{Mg}\left(\mathrm{NO}_{3}\right)_{2}$ plus $7.5 \mu \mathrm{g} \mathrm{Pd}$ $\left(\mathrm{NO}_{3}\right)_{2}$ for $\mathrm{Cu}$. $\mathrm{Ni}$ and Mo were analysed without the addition of matrix modifiers. All standard solutions were performed in $0.1 \mathrm{~mol} \cdot \mathrm{L}^{-1}$ nitric acid.

\subsubsection{Ultraviolet-visible molecular absorption spectrometry}

Ultraviolet-visible molecular absorption spectrometry (UV-VIS-MAS) was used to 
analyse P [4] using an 8265 UNICAM UV/ visible spectrometer (Thermo Electron Corpor., Cambridge, UK) at the maximum of absorption band with a cell size of $1 \mathrm{~cm}$ and $\lambda=690 \mathrm{~nm}$.

For the UV-VIS-MAS measurements, calibration blank and standard solutions were prepared following the same procedure as that for samples. The milk digestion solution A was diluted $\left(F_{\text {dil }}=100\right)$ before the measurements.

\subsubsection{Potentiometric titration}

ORION 420A potentiometer (Orion Research, Inc., USA) with an ORION $\mathrm{Ag}_{2} \mathrm{~S}$ electrode and INGOLD double calomel electrode as reference was used to determine chloride. Before starting the analysis, $\mathrm{AgNO}_{3} 0.01 \mathrm{~mol} \cdot \mathrm{L}^{-1}$ solution was standardized with $\mathrm{NaCl}$ standard solution.

All weights were measured using a calibrated Mettler Toledo AT 200 analytical balance, with $200 \mathrm{mg}$ capacity and $0.1 \mathrm{mg}$ readability.

\subsection{Validation and quality assurance methodologies}

Quality assurance/quality control programmes were developed for monitoring the methods performance characteristics and to demonstrate the reliability of the results. These include the calibration function characteristics, influence of the matrix on the calibration and assessment of contamination, precision and trueness of the overall procedures.

\subsubsection{Characteristics of calibration}

Atomic absorption and UV-visible molecular spectrometric techniques require calibration of the equipments since the absorbance of the sample digestion solution was compared with those of a set of CS solutions. For chloride, no calibration function was needed.
The calibration functions were calculated using regression analysis assuming that all errors are normally distributed in the $y$-axis. The linearity of the calibration curves was verified using Mandel's fitting test [10, 15]. Testing values (TV) were calculated based on the residual standard deviations of the first- and the second-order functions and the TV compared with the tabled $F$ value for $f_{1}=1, f_{2}=N-3$ and $P=99 \%, N$ being the number of calibration data pairs. Previously, the homogeneity of absorbance variances was verified by $F$ tests.

Variation coefficients of the calibration lines $\left(V_{\mathrm{xo}}\right)$ were calculated to assess the quality of calibration, since the residual standard deviations are a measure of the scatter of the values $[15,17]$.

After the establishment of the statistical performance characteristics of calibration functions, quality control actions with acceptance criteria were defined to be used in routine: the calibration blank absorbance, $B_{\mathrm{c}}$, should be $<0.005$ for $\mathrm{K}, \mathrm{Zn}$ and $\mathrm{Mn}$, 0.010 for $\mathrm{Na}$ and the elements analysed by ETAAS and $B_{\mathrm{c}}<0.015$ for $\mathrm{Ca}$ and $\mathrm{Mg}$; the squared correlation coefficient $\left(r^{2}\right)$ should be $>0.995$ and the intercept of the regression lines $(a)$ and $B_{\mathrm{c}}$ values should be related by the equation: $a=B_{\mathrm{c}} \pm 0.003$ to hold the lower analytical limits.

If the calibration function acceptance criteria fall outside the limits, then the calibration procedure was repeated after the corrective actions were taken [27].

The stability of the calibration curves was verified every six sample sets, at least, using QCS solutions: relative errors on QCS solutions concentration within $\pm 5 \%$ of the expected values for FAAS and $\pm 10 \%$ for ETAAS and UV-VIS-MAS were considered acceptable. Whenever the QCS values were outside the acceptance criteria, the measurements were repeated. If a second QCS measurement was again outside the limits, the equipment was recalibrated and the samples were reanalysed $[10,27]$. 


\subsubsection{Assessment of contamination}

The assessment of contamination was performed with calibration and reagent blank measurements $\left(B_{\text {reag }}\right)$ carried out in each batch of samples. Absorbance values for $B_{\text {reag }}<0.005$ for $\mathrm{K}$ and $\mathrm{Mn}, 0.010$ for $\mathrm{Zn}$; 0.015 for $\mathrm{Ca}$ and $\mathrm{Mg} ; 0.020$ for $\mathrm{Na}$ and the elements analysed by ETAAS were accepted. If the reagent blank absorbance differs from $B_{\mathrm{c}}$ values $>0.003$, then $B_{\text {reag }}$ and $B_{\mathrm{c}}$ values should be subtracted from the absorbance values of the samples and standard solutions, respectively. New calibration plot must be calculated.

\subsubsection{Limits of detection and limits of quantification}

Limit of detection $\left(C_{\mathrm{LOD}}\right)$ and limit of quantification $\left(C_{\mathrm{LOQ}}\right)$ expressed as concentration of the elements in the digestion solution $\left(\mathrm{mg} \cdot \mathrm{L}^{-1}\right)$ were estimated using International Union of Pure and Applied Chemistry recommendations [19]: $y_{\mathrm{L}}=$ $\bar{y}_{\mathrm{B}}+k s_{\mathrm{B}}, y_{\mathrm{L}}$ being the absorbance signal on the limits, $\bar{y}_{\mathrm{B}}$ the mean of blank measurements and $S_{\mathrm{B}}$ the standard deviation of the blank and $k$ a numerical factor $(k=3$ and $k=10$ for $C_{\mathrm{LOD}}$ and $C_{\mathrm{LOQ}}$, respectively) [19]. In this study, the intercept of the regression lines was used to $\bar{y}_{\mathrm{B}}$, and $s_{y 1}$ instead of $s_{\mathrm{B}}$ as recommended by Miller and Miller [21]. $C_{\mathrm{LOD}}$ values were calculated using equations (3) and (4) for first- and second-order calibration functions and $k=3$. For $C_{\mathrm{LOD}}$ and $C_{\mathrm{LOQ}}$, the same expressions were used with $k=10$ :

$$
\begin{gathered}
C_{\mathrm{LOD}}=\frac{k s_{y 1}}{b}, \\
C_{\mathrm{LOQ}}=-\frac{b}{2 c}-\sqrt{\left(\frac{b}{2 c}\right)^{2}+\frac{k s_{y 2}}{c},}
\end{gathered}
$$

where $s_{y 1}$ and $s_{y 2}$ are the residual standard deviation of first- and second-order calibration curves, respectively $[16,17], b$ and $c$ are the coefficients of the calibration functions.

Limits of detection (mass fraction) $\left(w_{\text {LOD }}\right)$ and limits of quantification (mass fraction) ( $\left.w_{\mathrm{LOQ}}\right)$ of the methods were calculated using equation (1) and the $C_{\mathrm{LOD}}$ and $C_{\mathrm{LOQ}}$ values for $C$ values, respectively. For chloride, $w_{\text {LOD }}$ was calculated as three times the standard deviation of spiked reagent blanks at a chloride range of $50 \mathrm{mg} \cdot \mathrm{kg}^{-1}$.

\subsubsection{Precision}

The precision was estimated from triplicate analysis. Acceptance criteria were previously established: each relative range $\left(R^{\mathrm{rel}}\right)$ should be $<10 \%$ for the elements analysed by UV-VIS-MAS and FAAS except for $\mathrm{Fe}$ and $\mathrm{Mn}\left(R^{\mathrm{rel}} \leq 20 \%\right)$, and $R^{\mathrm{rel}}$ $\leq 30 \%$ for ETAAS.

Relative standard deviations at intralaboratory reproducibility conditions $\left(\mathrm{RSD}_{R}\right)$ from $R$-charts of triplicates [10] were calculated. If results in milk are lower than the limits of quantification of the method, the precision will be evaluated from the acceptance criteria of triplicates assuming a rectangular distribution [18].

\subsubsection{Trueness}

Trueness was estimated in terms of overall recovery [6], obtained by analysing the independent sets of CRMs using the complete procedures: $\mathrm{BCR}-063 \mathrm{R}$ for $\mathrm{Na}$, $\mathrm{K}, \mathrm{Ca}, \mathrm{Mg}, \mathrm{P}, \mathrm{Cl}, \mathrm{Zn}$ and $\mathrm{Cu}$ and $\mathrm{BCR}-$ 151 for $\mathrm{Cd}$ and $\mathrm{Pb}$. For $\mathrm{Co}, \mathrm{Cr}$, Mo and $\mathrm{Ni}$ spiked milk samples were used since CRMs were not available.

The mean recoveries, $\bar{R}_{\mathrm{m}}$, were estimated by equation (5) or (6) for CRM or element spiked samples, respectively. Notice that the closer these ratios are to 1 , the less significant is the bias in the method [6].

The results were previously considered unbiased whenever $\bar{R}_{\mathrm{m}}$ were within the 
interval $1.00 \pm 0.10$ for $\mathrm{Ca}, \mathrm{K}, \mathrm{Mg}, \mathrm{Na}, \mathrm{Fe}$, $\mathrm{Mn}, \mathrm{Zn}$ and $\mathrm{Cl}$ and $1.00 \pm 0.20$ for trace elements $(\mathrm{Cd}, \mathrm{Cu}, \mathrm{Co}, \mathrm{Cr}$, Mo, Ni and $\mathrm{Pb})$. These last according to the European Regulation 333/2007/EC [25] requirements for $\mathrm{Pb}$ in milk:

$$
\begin{gathered}
\bar{R}_{\mathrm{m}}=\frac{\bar{w}_{\text {obs_CRM }}}{w_{\mathrm{CRM}}}, \\
\bar{R}_{\mathrm{m}}=\frac{\bar{w}_{\text {obs_spike }+ \text { sample }}-\bar{w}_{\text {obs_sample }}}{w_{\text {spike }}},
\end{gathered}
$$

where $\bar{w}_{\text {obs_sample }}, \bar{w}_{\text {obs_CRM }}$ and $\bar{w}_{\text {obs_spike+sample }}$ are the mean values of replicate analysis of the samples, the CRMs and spiked samples, respectively, $w_{\mathrm{CRM}}$ the certified value of the $\mathrm{CRM}$ and $w_{\text {spike }}$ the element spiked concentration.

\subsubsection{Measurement uncertainty}

The relative combined standard uncertainties, $u_{\mathrm{c}}^{\text {rel }}(w)$, were estimated from the contribution of the precision and trueness components according to equation (7). Precision is expressed as $\mathrm{RSD}_{R}$ and trueness was assessed as the relative uncertainty of the recovery, $u^{\text {rel }}\left(\bar{R}_{\mathrm{m}}\right)$. This approach further implies that $u^{\text {rel }}\left(\bar{R}_{\mathrm{m}}\right)$ is independent of the analyte concentration and RSD values are approximately constant within the working range $[6,9]$ :

$$
u_{\mathrm{c}}^{\mathrm{rel}}(w)=\sqrt{\mathrm{RSD}^{2}+u^{\mathrm{rel}}\left(\bar{R}_{\mathrm{m}}\right)} .
$$

The $u^{\text {rel }}\left(\bar{R}_{\mathrm{m}}\right)$ values were calculated by equation (8) if the trueness components were evaluated using CRMs and by equation (9) when $\bar{R}_{\mathrm{m}}$ were estimated from spiking studies:

$$
u^{\mathrm{rel}}\left(\bar{R}_{\mathrm{m}}\right)=\sqrt{\frac{1}{n}\left(\frac{S_{\text {obs_CRM }}}{\bar{w}_{\text {obs-CRM }}}\right)^{2}+\left(\frac{u\left(w_{\mathrm{CRM}}\right)}{\bar{w}_{\mathrm{CRM}}}\right)},
$$

$$
\begin{aligned}
& u^{\text {rel }}\left(\bar{R}_{\mathrm{m}}\right)= \\
& \sqrt{\frac{1}{n}\left(\frac{S_{\text {obs_spike+sample }}+S_{\text {sample }}}{\bar{w}_{\text {obs_spike+sample }}-\bar{w}_{\text {sample }}}\right)^{2}+\left(\frac{u\left(w_{\text {spike }}\right)}{\bar{w}_{\text {spike }}}\right)},
\end{aligned}
$$

where $n$ is the number of replicates, $S_{\text {obs CRM }}$ is the standard deviation of $\mathrm{CR} \bar{M}$ replicates, $u\left(w_{\mathrm{CRM}}\right)$ is the standard uncertainty of the certified value of the CRM, $S_{\text {obs_spike+sample }}$ and $S_{\text {sample }}$ are the standard deviations of spiked samples and sample, respectively, and $u\left(w_{\text {spike }}\right)$ is the standard uncertainty of spike on the milk sample estimated applying the general relationship between a result $Y$ and the associated input quantities for a model $Y=f\left(x_{1}, x_{2}, \ldots, x_{i}, \ldots, x_{n}\right)$, following the law of propagation of uncertainties for independent input quantities [18].

The statistic $t$ significant test was used to check if $\bar{R}_{\mathrm{m}}$ values were significantly different from 1 .

\section{RESULTS}

\subsection{Methods performance characteristics}

Table III shows the characteristics of calibration functions performance, that is, TV for Mandel linearity test, coefficients of variation and limits of detection $\left(C_{\mathrm{LOD}}\right)$ and limits of quantification $\left(C_{\mathrm{LOQ}}\right)$. The quality of regression analysis was judged using the $V_{\text {xo }}$ values.

Direct calibration curves were used, because matrix influence on each calibration functions was previously studied by spiking both milk and CRM digestion solutions with known amounts of analyte. Relative errors of $\pm 10 \%$ on the experimental values for FAAS and UV-VIS-MAS and $\pm 15 \%$ for ETAAS were considered acceptable. Otherwise, the standard addition method should be used to correct the possible matrix effects. 
Table III. Performance characteristics of calibration functions.

\begin{tabular}{lccrccc}
\hline Element & $\begin{array}{c}\text { Concentration range } \\
\left(\mathrm{mg} \cdot \mathrm{L}^{-1}\right)\end{array}$ & Absorbance range & $\mathrm{TV}$ & $V_{\text {xо }}$ & $\begin{array}{c}C_{\mathrm{LOD}} \\
\left(\mathrm{mg} \cdot \mathrm{L}^{-1}\right)\end{array}$ & $\begin{array}{c}C_{\mathrm{LOQ}} \\
\left(\mathrm{mg} \cdot \mathrm{L}^{-1}\right)\end{array}$ \\
\hline $\mathrm{Na}$ & $0.02-0.3$ & $0.02-0.21$ & 12.2 & 0.03 & 0.008 & 0.02 \\
$\mathrm{~K}$ & $0.02-0.5$ & $0.02-0.20$ & 7.2 & 0.02 & 0.008 & 0.02 \\
$\mathrm{Ca}$ & $0.02-4.0$ & $0.03-0.25$ & 2.8 & 0.03 & 0.07 & 0.2 \\
$\mathrm{Mg}$ & $0.02-0.2$ & $0.08-0.28$ & 34.1 & 0.02 & 0.008 & 0.02 \\
$\mathrm{Zn}$ & $0.02-0.4$ & $0.02-0.18$ & 0.1 & 0.03 & 0.007 & 0.02 \\
$\mathrm{Fe}$ & $0.1-1.0$ & $0.02-0.11$ & 1.2 & 0.05 & 0.03 & 0.10 \\
$\mathrm{Mn}$ & $0.025-0.50$ & $0.01-0.11$ & 1.1 & 0.01 & 0.001 & 0.004 \\
$\mathrm{P}$ & $0.05-1.0$ & $0.06-0.86$ & 278 & 0.11 & 0.01 & 0.03 \\
$\mathrm{Element}$ & Concentration range & Absorbance range & $\mathrm{TV}$ & $V_{\text {xо }}$ & $C_{\mathrm{LOD}}$ & $C_{\mathrm{LOQ}}$ \\
& $\left(\mu \mathrm{g} \cdot \mathrm{L}^{-1}\right)$ & & & & $\left(\mu \mathrm{g} \cdot \mathrm{L}^{-1}\right)$ & $\left(\mu \mathrm{g} \cdot \mathrm{L}^{-1}\right)$ \\
\hline $\mathrm{Cr}$ & $0.25-2.5$ & $0.02-0.12$ & -2.8 & 0.07 & 0.1 & 0.3 \\
$\mathrm{Mo}$ & $1-10$ & $0.02-0.12$ & 0.2 & 0.07 & 0.4 & 1.0 \\
$\mathrm{Ni}$ & $1-10$ & $0.02-0.07$ & 1.7 & 0.04 & 0.3 & 1.0 \\
$\mathrm{Cu}$ & $1-20$ & $0.02-0.30$ & -2.4 & 0.04 & 0.37 & 1.0 \\
$\mathrm{Cd}$ & $0.1-1.5$ & $0.02-0.22$ & -3.0 & 0.05 & 0.04 & 0.1 \\
$\mathrm{Co}$ & $0.5-7.5$ & $0.02-0.18$ & -2.8 & 0.08 & 0.2 & 0.6 \\
$\mathrm{~Pb}$ & $1-7.5$ & $0.02-0.10$ & -3.0 & 0.10 & 0.5 & 1.0 \\
\hline
\end{tabular}

$\mathrm{TV}$, testing value for linearity evaluation $\left(\mathrm{TV}=\mathrm{DS}^{2} / s_{y 2}^{2}\right.$, with $\left.\mathrm{DS}^{2}=(N-2) s_{y 1}^{2}-(N-3) s_{y 2}^{2}\right) ; V_{\mathrm{xo}}$, relative variation coefficient $[16,17] ; N$, number of calibration data pairs; $C_{\mathrm{LOD}}$, limit of detection and $C_{\mathrm{LOQ}}$, limit of quantification (both expressed as concentration of the elements in the milk digestion solutions).

Table IV presents a validation and quality assurance report, showing precision and trueness of the methods. As reported before, trueness was estimated as overall recovery. Limits of detection and limits of quantification (both mass fraction) of the methods are also shown. An intralaboratory approach based on validation and quality control data was used to estimate $u^{\text {rel }}(w)$ (equation (7)).

Tables V and VI show the results obtained with the CRMs and spiked samples, as well as the $u^{\text {rel }}\left(R_{\mathrm{m}}\right)$ values (equations $(8)$ and (9), respectively). Since the uncertainties of CRM were given by a confidence interval with $95 \%$, the $u\left(w_{\mathrm{CRM}}\right)$ values were obtained dividing those values by $2[6,8]$. A correction for bias was not considered because $\bar{R}_{\mathrm{m}}$ values were not significantly different from 1 , as the significance tests $t$ were lower than the coverage factor of 2 .

\subsection{Minerals and trace elements in goat milk}

The proposed validation and quality assurance programme for the characterization of minerals and trace elements was applied to milk samples of an indigenous Portuguese goat breed. Table VII shows these results with uncertainty estimation for Serpentina goat milk collected along the lactation period study.

\section{DISCUSSION}

From Table III, it can be concluded that linear calibration functions provided the best adjustment for all elements, except for $\mathrm{Mg}$ and $\mathrm{P}$, since the calculated TV, are lower than the critical Fisher values $\left(F_{1,4 ; 0.99}=\right.$ 21.2). A second order calibration function 
Table IV. Validation and quality assurance report.

\begin{tabular}{|c|c|c|c|c|c|c|c|c|}
\hline \multirow[t]{2}{*}{ Parameter } & \multicolumn{3}{|c|}{ Precision } & \multirow{2}{*}{$\begin{array}{c}\text { Trueness } \\
R_{\mathrm{m}} \pm u\left(\bar{R}_{\mathrm{m}}\right)\end{array}$} & \multirow{2}{*}{$\begin{array}{c}w_{\mathrm{LOD}} \\
\left(\mathrm{mg} \cdot \mathrm{kg}^{-1}\right)\end{array}$} & \multirow{2}{*}{$\begin{array}{c}w_{\mathrm{LOQ}} \\
\left(\mathrm{mg} \cdot \mathrm{kg}^{-1}\right)\end{array}$} & \multicolumn{2}{|c|}{ Uncertainty } \\
\hline & $\mathrm{RSD}_{R}$ & $\mathrm{RSD}_{\text {Horwitz }}$ & Horrat $_{R}$ & & & & $u_{\mathrm{c}}^{\mathrm{rel}}$ & $U_{\mathrm{f}}^{\mathrm{rel}}$ \\
\hline $\mathrm{Na}$ & 0.026 & 0.046 & 0.6 & $1.01 \pm 0.03^{\mathrm{a}}$ & 20 & 60 & 0.04 & 0.10 \\
\hline $\mathrm{K}$ & 0.022 & 0.037 & 0.6 & $0.96 \pm 0.01^{\mathrm{a}}$ & 20 & 60 & 0.03 & 0.10 \\
\hline $\mathrm{Ca}$ & 0.025 & 0.038 & 0.7 & $1.06 \pm 0.03^{\mathrm{a}}$ & 5.0 & 15 & 0.04 & 0.10 \\
\hline $\mathrm{Mg}$ & 0.019 & 0.054 & 0.4 & $1.06 \pm 0.06^{\mathrm{a}}$ & 5 & 15 & 0.06 & 0.10 \\
\hline $\mathrm{P}$ & 0.024 & 0.039 & 0.6 & $1.01 \pm 0.01^{\mathrm{a}}$ & 25 & 75 & 0.03 & 0.10 \\
\hline $\mathrm{Cl}$ & 0.021 & 0.037 & 0.6 & $1.01 \pm 0.02^{\mathrm{a}}$ & 0.03 & 0.1 & 0.03 & 0.10 \\
\hline $\mathrm{Zn}$ & 0.030 & 0.093 & 0.3 & $0.99 \pm 0.02^{\mathrm{a}}$ & 0.4 & 1.0 & 0.04 & 0.19 \\
\hline $\mathrm{Fe}$ & 0.068 & 0.13 & 0.5 & $0.90 \pm 0.07^{\mathrm{a}}$ & 0.04 & 0.11 & 0.11 & 0.19 \\
\hline $\mathrm{Mn}$ & 0.036 & 0.16 & 0.2 & $0.93 \pm 0.04^{\mathrm{a}}$ & 0.001 & 0.004 & 0.06 & 0.15 \\
\hline $\mathrm{Cr}$ & 0.12 & 0.23 & 0.5 & $1.09 \pm 0.11^{\mathrm{c}}$ & 0.0003 & 0.001 & 0.15 & 0.20 \\
\hline $\mathrm{Cu}$ & 0.12 & 0.16 & 0.7 & $1.02 \pm 0.02^{\mathrm{a}}$ & 0.001 & 0.004 & 0.10 & 0.18 \\
\hline $\mathrm{Cu}$ & 0.12 & 0.16 & 0.7 & $0.96 \pm 0.05^{\mathrm{b}}$ & 0.001 & 0.004 & 0.12 & 0.18 \\
\hline Mo & 0.11 & 0.18 & 0.6 & $1.13 \pm 0.10^{\mathrm{c}}$ & 0.001 & 0.004 & 0.13 & 0.20 \\
\hline $\mathrm{Ni}$ & 0.087 & 0.31 & 0.3 & $0.83 \pm 0.07^{\mathrm{c}}$ & 0.001 & 0.004 & 0.10 & 0.30 \\
\hline $\mathrm{Cd}$ & 0.087 & 0.42 & 0.2 & $1.02 \pm 0.07^{\mathrm{b}}$ & 0.0002 & 0.0006 & 0.11 & 0.22 \\
\hline $\mathrm{Cd}$ & 0.087 & 0.42 & 0.2 & $1.11 \pm 0.07^{\mathrm{c}}$ & 0.0002 & 0.0006 & 0.10 & 0.22 \\
\hline $\mathrm{Co}$ & 0.087 & 0.34 & 0.3 & $0.87 \pm 0.05^{\mathrm{c}}$ & 0.0007 & 0.002 & 0.10 & 0.26 \\
\hline $\mathrm{Pb}$ & 0.087 & 0.28 & 0.3 & $1.01 \pm 0.05^{\mathrm{b}}$ & 0.002 & 0.007 & 0.10 & 0.32 \\
\hline $\mathrm{Pb}$ & 0.087 & 0.28 & 0.3 & $1.01 \pm 0.05^{\mathrm{c}}$ & 0.002 & 0.007 & 0.10 & 0.32 \\
\hline
\end{tabular}

$\mathrm{RSD}_{R}$, relative standard deviation $\left(\mathrm{RSD}=\left(\bar{R} / d_{2}\right) / \bar{w}_{R \text {-chart }} ; d_{2}=1.693\right.$ for triplicates $)$ [10]; $\mathrm{RSD}_{\text {Horwitz }}$, relative standard deviation calculated by Horwitz formula $\operatorname{RSD}_{\text {Horwitz }}=2^{\left({ }^{-0}-5 \log w\right)} ; u\left(\bar{R}_{\mathrm{m}}\right)$, standard uncertainty of $\bar{R}_{\mathrm{m}}$ given by $u\left(\bar{R}_{\mathrm{m}}\right)=\bar{R}_{\mathrm{m}} \times u^{\text {rel }}\left(\bar{R}_{\mathrm{m}}\right)$, where $u^{\text {rel }}\left(\bar{R}_{\mathrm{m}}\right)$ values were calculated by equation (8) or $(9) ; w_{\text {LOD }}$ limit of detection (mass fraction); $w_{\mathrm{LOQ}}$, limit of quantification (mass fraction); $u_{\mathrm{c}}^{\text {rel }}$, relative combined uncertainty (equation (7)); $U_{\mathrm{f}}^{\text {rel }}$, maximum standard uncertainty (equation (10)).

${ }^{a}$ Data from Table V (CRM BCR - 063R).

${ }^{\mathrm{b}}$ Data from Table V (CRM BCR - 155).

${ }^{\mathrm{c}}$ Data from Table VI (spiked milk samples).

was used for $\mathrm{P}$ and $\mathrm{Mg}(\mathrm{TV}>F)$. $V_{\text {xo }}$ values around $5 \%$ for FAAS and $10 \%$ for ETAAS indicate that the precision of calibrations are acceptable [28]. Values of $V_{\text {xo }}$ close to those were obtained. For

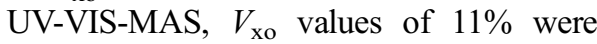
obtained due to the high concentration range of the calibration. $C_{\mathrm{LOQ}}$ values are close to the lowest concentration of the calibration range fulfilling the requirement that $C_{\mathrm{LOQ}}$ values correspond to the lower limit of quantitative measurements [10]. These limits depend on the precision of the regression and they should be checked on a daily basis [27].
Table IV shows that $\mathrm{RSD}_{R}$ values were $<0.05$ or 0.10 , which indicates the good precision of the FAAS and ETAAS procedures. In food control, the precision of the methods are also assessed using the Horrat values, that is, the ratio between $\mathrm{RSD}_{R}$ and those obtained from the Horwitz formula, $\mathrm{RSD}_{\text {Horwitz }}[1,22]$. Horrat values $<2$, as required by the European Regulation $333 / 2007 / \mathrm{EC}$ for $\mathrm{Pb}$ in milk [25], were observed.

The data on the recoveries of minerals and trace metals obtained from CRMs and spiked sample analysis in Table IV show that $\bar{R}_{\mathrm{m}}$ values ranged between 0.9 and 1.1 
Table V. Relative standard uncertainty of trueness component estimated from CRM recovery analysis.

\begin{tabular}{|c|c|c|c|c|c|c|c|}
\hline Element & Method & $w_{\mathrm{CRM}}\left(\mathrm{mg} \cdot \mathrm{kg}^{-1}\right)$ & $u\left(w_{\mathrm{CRM}}\right)\left(\mathrm{mg} \cdot \mathrm{kg}^{-1}\right)$ & $\vec{w}_{\text {obs_CRM }}\left(\mathrm{mg} \cdot \mathrm{kg}^{-1}\right)$ & $S_{\text {obs_CRM }}\left(\mathrm{mg} \cdot \mathrm{kg}^{-1}\right)$ & $u^{\mathrm{rel}}\left(\bar{R}_{\mathrm{m}}\right)$ & $t_{\mathrm{cal}}$ \\
\hline$\overline{\mathrm{Na}}$ & FAAS & $4.37 \times 10^{3}$ & $0.015 \times 10^{3}$ & $4.37 \times 10^{3}$ & $0.03 \times 10^{3}$ & 0.027 & 0.5 \\
\hline $\mathrm{K}$ & & $17.68 \times 10^{3}$ & $0.095 \times 10^{3}$ & $17.05 \times 10^{3}$ & $0.49 \times 10^{3}$ & 0.013 & 1.9 \\
\hline $\mathrm{Ca}$ & & $13.49 \times 10^{3}$ & $0.05 \times 10^{3}$ & $14.00 \times 10^{3}$ & $0.78 \times 10^{3}$ & 0.023 & 1.9 \\
\hline $\mathrm{Mg}$ & & $1.263 \times 10^{3}$ & $0.012 \times 10^{3}$ & $1.27 \times 10^{3}$ & $0.032 \times 10^{3}$ & 0.055 & 1.1 \\
\hline $\mathrm{Zn}$ & & 49.0 & 0.3 & 48.9 & 1.1 & 0.016 & 0.3 \\
\hline $\mathrm{Fe}$ & & 2.32 & 0.12 & 2.06 & 0.27 & 0.081 & 0.4 \\
\hline $\mathrm{P}$ & UV-VIS-MAS & $11.10 \times 10^{3}$ & $0.065 \times 10^{3}$ & $11.10 \times 10^{3}$ & $0.33 \times 10^{3}$ & 0.013 & 0.5 \\
\hline $\mathrm{Cl}$ & Potentiometry & $9.94 \times 10^{3}$ & $0.15 \times 10^{3}$ & $10.02 \times 10^{3}$ & $0.32 \times 10^{3}$ & 0.020 & 0.6 \\
\hline $\mathrm{Cu}$ & ETAAS & 0.602 & 0.010 & 0.611 & 0.015 & 0.020 & 1.0 \\
\hline $\mathrm{Cu}$ & & 5.23 & 0.041 & 5.00 & 0.43 & 0.05 & 0.92 \\
\hline $\mathrm{Cd}$ & & 0.101 & 0.004 & 0.103 & 0.009 & 0.064 & 0.4 \\
\hline $\mathrm{Pb}$ & & 2.002 & 0.013 & 2.02 & 0.18 & 0.050 & 0.2 \\
\hline
\end{tabular}

$w_{\text {CRM }}$, certified value of the CRM; $u\left(w_{\text {CRM }}\right)$, standard uncertainty of the certified value of the CRM; $\vec{w}_{\text {obs CRM }}$, mean value of CRM replicate analysis

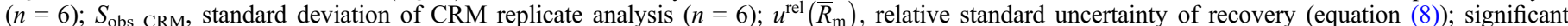
statistic test $\bar{c}_{\text {cal }}=\left(\left|1-\bar{R}_{\mathrm{m}}\right|\right) / u^{\text {rel }}\left(\bar{R}_{\mathrm{m}}\right)[6]$. 
Table VI. Relative standard uncertainty of trueness component estimated from spiked milk samples.

\begin{tabular}{|c|c|c|c|c|c|c|c|c|}
\hline Element & Method & $\begin{array}{c}\bar{w}_{\text {sample }} \\
\left(\mathrm{mg} \cdot \mathrm{kg}^{-1}\right)\end{array}$ & $\begin{array}{c}w_{\text {spike }} \\
\left(\mathrm{mg} \cdot \mathrm{kg}^{-1}\right)\end{array}$ & $\begin{array}{c}u\left(w_{\text {spike }}\right) \\
\left(\mathrm{mg} \cdot \mathrm{kg}^{-1}\right)\end{array}$ & $\begin{array}{c}w_{\text {obs_spike+sample }} \\
\left(\mathrm{mg} \cdot \mathrm{kg}^{-1}\right)\end{array}$ & $\begin{array}{c}S_{\text {obs_spike+sample }} \\
\left(\mathrm{mg} \cdot \mathrm{kg}^{-1}\right)\end{array}$ & $u^{\mathrm{rel}}\left(\bar{R}_{\mathrm{m}}\right)$ & $t_{\mathrm{cal}}$ \\
\hline \multirow[t]{3}{*}{$\mathrm{Mn}$} & \multirow[t]{3}{*}{ FAAS } & 0.14 & 0.097 & 0.001 & 0.24 & 0.009 & 0.11 & 0.2 \\
\hline & & 0.14 & 0.093 & 0.001 & 0.23 & 0.008 & 0.11 & 0.8 \\
\hline & & 0.14 & 0.25 & 0.001 & 0.36 & 0.013 & 0.06 & 1.8 \\
\hline \multirow[t]{2}{*}{$\mathrm{Cr}$} & \multirow[t]{2}{*}{ ETAAS } & 0.038 & 0.0041 & 0.00007 & 0.0089 & 0.00087 & 0.17 & 1.5 \\
\hline & & 0.038 & 0.010 & 0.00017 & 0.013 & 0.00087 & 0.13 & 0.58 \\
\hline \multirow[t]{3}{*}{ Mo } & \multirow[t]{3}{*}{ ETAAS } & 0.029 & 0.010 & 0.00017 & 0.015 & 0.0015 & 0.14 & 1.8 \\
\hline & & 0.029 & 0.009 & 0.00017 & 0.012 & 0.0012 & 0.15 & 0.4 \\
\hline & & 0.029 & 0.020 & 0.00033 & 0.025 & 0.0028 & 0.13 & 0.9 \\
\hline \multirow[t]{4}{*}{$\mathrm{Cd}$} & \multirow[t]{4}{*}{ ETAAS } & - & 0.0020 & 0.00005 & 0.0021 & 0.00019 & 0.09 & 1.0 \\
\hline & & - & 0.0020 & 0.00005 & 0.0021 & 0.00019 & 0.09 & 1.2 \\
\hline & & - & 0.0051 & 0.00010 & 0.0060 & 0.00052 & 0.09 & 1.9 \\
\hline & & - & 0.0050 & 0.00010 & 0.0060 & 0.00052 & 0.09 & 2.0 \\
\hline \multirow[t]{4}{*}{$\mathrm{Pb}$} & \multirow[t]{4}{*}{ ETAAS } & - & 0.019 & 0.0030 & 0.0022 & 0.0019 & 0.09 & 1.3 \\
\hline & & & 0.039 & 0.0070 & 0.0046 & 0.0039 & 0.09 & 1.8 \\
\hline & & - & 0.039 & 0.0070 & 0.0040 & 0.0034 & 0.09 & 0.1 \\
\hline & & - & 0.060 & 0.0012 & 0.0065 & 0.0057 & 0.09 & 0.9 \\
\hline \multirow[t]{2}{*}{$\mathrm{Ni}$} & \multirow[t]{2}{*}{ ETAAS } & - & 0.014 & 0.00025 & 0.012 & 0.0011 & 0.08 & 1.7 \\
\hline & & - & 0.014 & 0.00025 & 0.011 & 0.0010 & 0.08 & 2.0 \\
\hline \multirow[t]{2}{*}{ Co } & \multirow[t]{2}{*}{ ETAAS } & - & 0.014 & 0.00025 & 0.012 & 0.0011 & 0.09 & 1.6 \\
\hline & & & 0.014 & 0.00025 & 0.011 & 0.0010 & 0.09 & 2.0 \\
\hline
\end{tabular}

$\bar{w}_{\text {sample }}$, mass fraction of each element; $w_{\text {spike }}$, mass fraction of the spiked element; $u\left(w_{\text {spike }}\right)$, standard

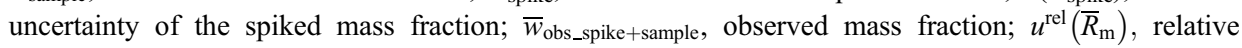
standard uncertainty of the recovery; $u^{\text {rel }}\left(\bar{R}_{\mathrm{m}}\right)$, relative standard uncertainty of the mean recovery (equation (9)); $t_{\text {cal, }}$, significant statistic test $t_{\text {cal }}=\left(\left|1-\bar{R}_{\mathrm{m}}\right|\right) / u^{\mathrm{rel}}\left(\bar{R}_{\mathrm{m}}\right)[6] ;-$, results lower than the limit of quantification (mass fraction).

and are within the limits that are previously established. In case of $\mathrm{Cd}$ and $\mathrm{Pb}$, the mass fraction of the certified values for the BCR -151 are considerably different from those values in the milk samples. In these conditions, spiked samples were also analysed for both elements at lower mass fractions and no evidence of loss of the analytes was detected since the recovery criterion was fulfilled $\left(0.8<\bar{R}_{\mathrm{m}}<1.2\right)$.

$w_{\text {LOD }}$ and $w_{\text {LOQ }}$ values in milk met the performance criteria required for the limits of detection and quantification of $\mathrm{Pb}$ in milk imposed by EC Regulation 1881/2006 [24] amended by $629 / 2008$ [26] $\left(w_{\mathrm{LOD}(\mathrm{Pb})}=\right.$ $4 \mu \mathrm{g} \cdot \mathrm{kg}^{-1}$ and $\left.w_{\mathrm{LOQ}(\mathrm{Pb})}=8 \mu \mathrm{g} \cdot \mathrm{kg}^{-1}\right)$.

The Directive 2005/4/EC [23] inserted a new performance criterion to assess the fitness of analytical methods to be used in food control based on uncertainty function approach to calculate a maximum standard uncertainty, $U_{\mathrm{f}}$, following equation:

$$
U_{\mathrm{f}}^{\mathrm{rel}}=\frac{U_{\mathrm{f}}}{w} \sqrt{\left(\frac{\mathrm{LOD}}{2}\right)^{2}+(a w)^{2}},
$$


Table VII. Mean values and uncertainty for minerals and trace elements content for Serpentina goat milk along the lactation period studied ${ }^{* *}$.

\begin{tabular}{|c|c|c|c|c|c|c|c|c|}
\hline \multirow{2}{*}{\multicolumn{2}{|c|}{$\begin{array}{l}\text { Minerals and } \\
\text { trace elements }\end{array}$}} & \multicolumn{7}{|c|}{ Lactation period (Nov-07 till May-08) } \\
\hline & & \multirow{2}{*}{$\begin{array}{c}\text { Nov-07 } \\
0.30 \pm 0.02\end{array}$} & \multirow{2}{*}{$\begin{array}{c}\text { Dec-07 } \\
0.36 \pm 0.03\end{array}$} & \multirow{2}{*}{$\begin{array}{c}\text { Jan-08 } \\
0.39 \pm 0.03\end{array}$} & \multirow{2}{*}{$\begin{array}{c}\text { Feb-08 } \\
0.38 \pm 0.03\end{array}$} & \multirow{2}{*}{$\begin{array}{c}\text { Mar-08 } \\
0.36 \pm 0.03\end{array}$} & \multirow{2}{*}{$\begin{array}{c}\text { Apr-08 } \\
0.38 \pm 0.04\end{array}$} & \multirow{2}{*}{$\begin{array}{c}\text { May-08 } \\
0.38 \pm 0.04\end{array}$} \\
\hline $\mathrm{Na}$ & $\left(\mathrm{g} \cdot \mathrm{kg}^{-1}\right)$ & & & & & & & \\
\hline $\mathrm{K}$ & & $1.3 \pm 0.3$ & $1.4 \pm 0.3$ & $1.5 \pm 0.3$ & $1.5 \pm 0.3$ & $1.4 \pm 0.3$ & $15 \pm 0.3$ & $1.4 \pm 0.3$ \\
\hline $\mathrm{Ca}$ & & $1.6 \pm 0.1$ & $1.48 \pm 0.09$ & $1.7 \pm 0.1$ & $1.56 \pm 0.09$ & $1.53 \pm 0.09$ & $1.33 \pm 0.08$ & $1.50 \pm 0.09$ \\
\hline $\mathrm{Mg}$ & & $0.13 \pm 0.02$ & $0.12 \pm 0.02$ & $0.14 \pm 0.02$ & $0.14 \pm 0.02$ & $0.13 \pm 0.02$ & $0.11 \pm 0.01$ & $0.13 \pm 0.02$ \\
\hline $\mathrm{P}$ & & $1.1 \pm 0.1$ & $1.2 \pm 0.1$ & $1.2 \pm 0.01$ & $1.1 \pm 0.1$ & $1.1 \pm 0.1$ & $1.2 \pm 0.1$ & $1.1 \pm 0.1$ \\
\hline $\mathrm{Cl}$ & & $1.5 \pm 0.1$ & $1.5 \pm 0.1$ & $1.4 \pm 0.1$ & $1.5 \pm 0.1$ & $15 \pm 0.1$ & $1.5 \pm 0.1$ & $1.6 \pm 0.1$ \\
\hline $\mathrm{Zn}$ & $\left(\mathrm{mg} \cdot \mathrm{kg}^{-1}\right)$ & $5.3 \pm 0.4$ & $4.9 \pm 0.4$ & $4.6 \pm 0.4$ & $4.4 \pm 0.4$ & $3.8 \pm 0.3$ & $4.2 \pm 0.3$ & $4.0 \pm 0.3$ \\
\hline $\mathrm{Fe}$ & & $0.46 \pm 0.03$ & $0.31 \pm 0.03$ & $0.52 \pm 0.03$ & $0.36 \pm 0.02$ & $0.38 \pm 0.02$ & $0.32 \pm 0.02$ & $0.35 \pm 0.02$ \\
\hline $\mathrm{Mn}$ & & $0.11 \pm 0.01$ & $0.13 \pm 0.01$ & $0.12 \pm 0.01$ & $0.11 \pm 0.01$ & $0.12 \pm 0.01$ & $0.074 \pm 0.004$ & $0.068 \pm 0.004$ \\
\hline $\mathrm{Cr}$ & $\left(\mu \mathrm{g} \cdot \mathrm{kg}^{-1}\right)$ & $3.2 \pm 0.7$ & $2.1 \pm 0.5$ & $18 \pm 4$ & $15 \pm 3$ & $11 \pm 2$ & $14 \pm 3$ & $11 \pm 2$ \\
\hline $\mathrm{Cu}$ & & $157 \pm 30$ & $70 \pm 14$ & $47 \pm 8$ & $43 \pm 8$ & $54 \pm 10$ & $29 \pm 5$ & $45 \pm 9$ \\
\hline Mo & & $3.8 \pm 1.0$ & $5.5 \pm 1.2$ & $4.4 \pm 1.1$ & $4.2 \pm 1.1$ & $1.9 \pm 0.5$ & $7.1 \pm 1.9$ & $11 \pm 3$ \\
\hline
\end{tabular}

$\mathrm{Ni}, \mathrm{Cd}, \mathrm{Co}$ and $\mathrm{Pb}$ results were lower than the limit of quantification (mass fraction) shown in Table IV.

* Results are on wet weight basis. 
where $a$ is a numeric factor depending on the value of $w$.

As can be noted in Table IV, the methodologies studied to characterize minerals and trace metals in milk gave results with combined uncertainty less than $U_{\mathrm{f}}$. This indicates that the "uncertainty function approach" requirement was fulfilled and the methods presented are suitable to be used in laboratories of milk analysis.

The relative expanded uncertainty, $U_{\exp }^{\text {rel }}(w)$, was obtained by multiplying the combined standard uncertainty (Tab. IV) by the coverage factor $(k)$ of 2 , which gives an interval with $\sim 95 \%$ confidence [8].

Methods used for characterization of minerals and trace elements in goat milk comply with EC requirements applied to methods of analysis for the official control since they are specific. Also, the Horrat values are $<2$ and recoveries are within the interval $1.00 \pm 0.10$ for minerals and $1.00 \pm 0.20$ for trace metals. Combined uncertainty estimation of the results was lower than the maximum standard uncertainty calculated using the uncertainty function approach.

Results for minerals and trace elements in Serpentina goat milk shown in Table VII were obtained following quality procedures, which assure confidence in both methods used and results. A harmonized performance criterion for evaluation of the methods of analysis and uncertainties within each food sector is surely needed, to warrant confidence in the results and allow comparability of data. Such approach is even more important concerning trace elements in milk, particularly the ones that are potentially toxic. At present, for milk sector, only $\mathrm{Pb}$ has a limit value considered in EC regulations.

Acknowledgements: The authors are grateful to the Serpentina Goat Association (APCRS), particularly to Eng ${ }^{\circ}$ A. Cachatra for his invaluable collaboration and support in supplying goat milk samples. Special thanks are due to F. Mouro and A. Fernandes for their collaboration in the atomic absorption spectrometric techniques and. A. Moreira for the determination of total phosphorous.

\section{REFERENCES}

[1] Alber R., Horwitz W., A heuristics derivation of the Horwitz curve, Anal. Chem. 69 (1997) 789-790.

[2] Alférez M.J.M., López-Aliaga I., Nestares T., Díaz-Castro J., Barrionuevo M., Ros P.B., Campos M.S., Dietary goat milk improves iron bioavailability in rats with induced ferropenic anaemia, in comparison with cow milk, Int. Dairy J. 16 (2006) 813-821.

[3] APHA - AWWA-WPCF, 3113 - metals by electrothermal atomic absorption spectrometry, in: Standard Methods for the Examination of Water and Wastewater, 21st edn., American Public Health Association, Washington, USA, 2005, pp. 3-25-3-32.

[4] APHA - AWWA-WPCF, 4500-PD - stannous chloride method, in: Standard Methods for the Examination of Water and Wastewater, 21st edn., American Public Health Association, Washington, USA, 2005, pp. 4-152-4-153.

[5] Barrionuevo M., Alférez M.J.M., LópezAliaga I., Sanz Sampelayo M.R., Campos M.S., Beneficial effect of goat milk on nutritive utilization of iron and copper in malabsorption syndrome, J. Dairy Sci. 85 (2002) 657-664.

[6] Barwick V.J., Ellison S.L.R., VAM Project 3.2.1 - Development and Harmonization of Measurement Uncertainty Principles. Part d: Protocol for Uncertainty Evaluation from Validation Data, LGC (Teddington) Ltd. Publishers, Weinheim, Germany, 2000.

[7] Campos M.S., Barrionuevo M., Alférez M.J.M., Nestares T., Díaz-Castro J., Ros P.B., Ortega E., López-Aliaga I., Consumption of caprine milk improves metabolism of calcium and phosphorus in rats with nutritional ferropenic anaemia, Int. Dairy J. 17 (2007) 412-419.

[8] EURACHEM/CITAC, Guide CG 4 Quantifying Uncertainty in Analytical Measurement, 2nd edn., 2000 [www.eurachem. com/QUAM2000-1.pdf].

[9] Eurolab Measurement Uncertainty Revisited, Alternative Approaches to Uncertainty Evaluation, Technical Report No. 1/2007, March 2007 [http://www.eurolab.org]. 
[10] Funk W., Dammann V., Donnevert G., Quality Assurance in Analytical Chemistry, VCH, Weinheim, Germany, 1995.

[11] Gran G., Equivalence volumes in potentiometric titrations, Anal. Chim. Acta 206 (1988) 111-123.

[12] Guler Z., Levels of 24 minerals in local goat milk, its strained yoghurt and salted yoghurt (tuzlu yogurt), Small Ruminant Res. 71 (2007) 130-137.

[13] Haouet N.M., Chessa G., Fiorini L., Galarini R., Estimation of uncertainty for the determination of mercury in food by CVAAS, Accred. Qual. Assur. 11 (2006) 17-22.

[14] ISO 5943 IDF 88, Cheese and Processed Cheese Products - Determination of Chloride Content - Potentiometric Titration Method, International Organization for Standardization, Brussels, Belgium, 2006.

[15] ISO 8070 IDF 119, Milk and Milk Products - Determination of Calcium, Sodium, Potassium and Magnesium Contents - Atomic Absorption Spectrometric Method, International Organization for Standardization, Brussels, Belgium, 2007.

[16] ISO 8466-1, Water quality - Calibration and Evaluation of Analytical Methods and Estimation of Performance Characteristics. Part 1: Statistical Evaluation of the Linear Calibration Function, International Organization for Standardization, Geneva, Switzerland, 1990.

[17] ISO 8466-2, Water quality - Calibration and Evaluation of Analytical Methods and Estimation of Performance Characteristics. Part 2: Calibration Strategy for Non-linear Second-Order Calibration Functions, International Organization for Standardization, Geneva, Switzerland, 2001.

[18] ISO GUM, Guide to the Expression of the Uncertainty in Measurement, International Organization for Standardization, Geneva, Switzerland, 1995.
[19] IUPAC - International Union of Pure and Applied Chemistry, Nomenclature symbols units and their usage in spectrochemical analysis - II data interpretation, analytical chemistry division, Spectrochim. Acta Part B 33 (1978) 241-245.

[20] Kondyli E., Katsiari C., Voutsinas L.P., Variations of vitamin and mineral contents in raw goat milk of the indigenous Greek breed during lactation, Food Chem. 100 (2007) 226-230.

[21] Miller J.C., Miller J.N., Statistics and Chemometrics for Analytical Chemistry, 4th edn., Prentice Hall, England, 2000.

[22] Noel L., Carl M., Vastel C., Guérin T., Determination of sodium, calcium, and magnesium content in milk products by flame atomic absorption spectrometry (FAAS): a joint ISO/IDF collaborative study, Int. Dairy J. 18 (2008) 899-904.

[23] Official journal of the European Communities (2005) L19/50, Commission Directive 2005/4/EC.

[23] Official Journal of the European Communities (2005) L19/50, Commission Directive 2005/4/EC.

[24] Official Journal of the European Union (2006) L364/5, Commission Regulation (EC) no. 1881/2006 of 19 December 2006.

[25] Official Journal of the European Union (2007) L88/29, Commission Regulation (EC) no. 333/2007 of 28 March 2007.

[26] Official Journal of the European Union (2008) L173/6, Commission Regulation, no. 629/2008 of 2 July 2008 .

[27] Trancoso M.A., Correia dos Santos M.M., Gonçalves M.L.S., Quality assurance program for the chemical characterization of soils, Accredit. Qual. Assur. 8 (2003) 323-333.

[28] Welz B., Sperling M., Atomic Absorption Spectrometry, 3rd edn., Wiley-VCH, Weinheim, Germany, 1999. 